\title{
Is the impact of high reward sensitivity and poor cognitive control on adolescent risk-taking more visible in rewarding conditions?
}

\author{
Joanna Fryt ${ }^{1}$ (D) $\cdot$ Tomasz Smoleń $^{2} \cdot$ Karolina Czernecka $^{1} \cdot$ Monika Szczygieł $^{1} \cdot$ Amelia La Torre $^{3}$
}

Accepted: 20 April 2021 / Published online: 3 May 2021

(C) The Author(s) 2021

\begin{abstract}
Adolescents are expected to take more risks than adults. The presented study was designed to determine whether adolescent risktaking results from high reward sensitivity and poor cognitive control. In particular, we aimed to examine whether the impact of these variables is more visible in rewarding than non-rewarding conditions. Ninety adolescents (aged 13-16) and 95 young adults (aged 20-28) took part in the study. We used a driving task in rewarded and non-rewarded conditions to measure risk-taking. We also used tasks measuring reward sensitivity, cognitive control and impulsivity. Additionally we used self-report measures of reward sensitivity, self-control and everyday risk-taking to see whether the effects observed for self-reports mimic the effects observed for behavioral tasks. We found that the higher the reward sensitivity, the more adolescents (but not adults) risk in the rewarded condition of a driving task. We found no impact of cognitive control or impulsivity on risk-taking, regardless of age and condition. At the self-report level, we found that the higher the reward sensitivity and the poorer the self-control, the more both adolescents and adults displayed everyday risk-taking behavior.
\end{abstract}

Keywords Adolescent risk-taking $\cdot$ Reward sensitivity $\cdot$ Cognitive control $\cdot$ Impulsivity

Adolescence is frequently characterized by increased risk-taking, sensation seeking and impulsivity (Defoe et al. 2015; Shulman et al. 2016). According to the most common definition formulated in decision science (Figner and Weber 2011), risk-taking is an activity that can potentially result in positive and negative outcomes, and the greater the variability of what may happen, the greater the risk. The Dual Systems Model (Steinberg 2008; see also an alternative formulation in Casey et al. 2008, and Luna and Wright 2016) explains adolescent risk-taking in terms of brain development.

According to the model, in adolescence the reward system is highly sensitive to incentives, which results in a propensity for exciting, novel and risky activities, while cognitive control system has not yet matured enough to successfully suppress potentially hazardous impulses (Shulman et al. 2016). For behavioral studies this means we should observe the

Joanna Fryt

joanna.fryt@up.krakow.pl

1 Institute of Psychology, Pedagogical University of Krakow, Podchorazych 2, 30-084 Krakow, Poland

2 Institute of Philosophy, Jagiellonian University, Krakow, Poland

3 Institute of Psychology, Jagiellonian University, Krakow, Poland independent or interactive impact of high reward sensitivity and poor cognitive control on risk-taking. This impact, moreover, should vary as a function of age (it should increase in adolescence and decrease after young adulthood; Duell et al. 2016).

High reward sensitivity and its impact on risk-taking in adolescence are well documented in neuroscientific and behavioral studies (van Duijvenvoorde et al. 2016; Shulman et al. 2016). At the self-report level, reward sensitivity is usually measured with sensation seeking (e.g. Harden et al. 2012) or strength of inhibition/activation (e.g., BIS/BAS questionnaires, Kim-Spoon et al. 2016). At the behavioral level it is measured with decision-making tasks such as the Columbia Card Task (e.g. Duijvenvoorde et al. 2015) or the Iowa Gambling Task (e.g. Duell et al. 2016), both of which are modified to separate indicators of reward sensitivity and risk-taking. An alternative tool is the Point Score Reaction Time Task (e.g. Meisel et al. 2019), which assesses the degree to which reaction times decline during rewarded compared to non-rewarded blocks.

Poor cognitive control and its possible impact on risktaking in adolescence have not been thoroughly examined. Although neuroscientific research indicates that the cognitive control system develops until adulthood (Casey 2015; Crone and Steinbeis 2017), and there is some evidence that this 
development underlies a decline in risk-taking over time (e.g. Qu et al. 2015), few studies have found a link between cognitive control and risk-taking at the behavioral level. For example, Botdorf et al. (2017) showed that adolescent risk-taking in a driving task is not related to cognitive control unless it is measured under arousal. Blair et al. (2018) found that risktaking in the Balloon Analogue Risk Task is not related to executive functions, but learning and performance in this task are (see also Figner et al. 2009). Cognitive control is defined in different ways and measured with various, often uncorrelated tools (Harden et al. 2017). At the self-report level it is usually measured with impulsivity (e.g. Vazsonyi and Ksinan 2017) and self-control questionnaires (e.g. Peeters et al. 2017). At the behavioral level, the most common tasks assess inhibition (e.g. Botdorf et al. 2017), working memory (e.g. Blair et al. 2018), and planning (e.g. Duell et al. 2016).

The impact of high reward sensitivity and poor cognitive control on risk-taking in adolescence has rarely been tested in behavioral studies (Shulman et al. 2016). Such research has increased in recent years (Duell et al. 2016; Kim-Spoon et al. 2016; Peeters et al. 2017; Vazsonyi and Ksinan 2017; Meisel et al. 2019). In cases in which research focuses on negative risks such as rule breaking and substance use, an interactive impact of high reward sensitivity and poor cognitive control on adolescent behavior is usually found. For example, KimSpoon et al. (2016) showed that high reward sensitivity predicts earlier onset of substance use in adolescents with poor (but not high) cognitive control. Peeters et al. (2017) found that better cognitive control at age 11 predicts lower probability of substance use at age 16, and this effect is stronger in those with high reward sensitivity. Vazsonyi and Ksinan (2017) showed that the greater the discrepancy between selfreported sensation seeking and impulsivity in adolescence, the more problem behaviors occur. In contrast, Duell et al. (2016), who assessed risk-taking with behavioral tasks and self-report questionnaires, found that the impact of high reward sensitivity and poor cognitive control on risk-taking is independent, not interactive. Moreover, the impact of poor cognitive control on risk-taking was not found in Asian or low-GDP countries, while in high-GDP countries it was apparent only among the oldest participants (26-30 years). Among the discussed explanations (e.g. cultural differences) Duell et al. (2016) suggest that the impact of the studied variables may be more visible when risk is taken in arousing situations.

According to the Dual Systems Model, increased risktaking in adolescents, compared to young adults, does not manifest all the time but only under situations of high arousal (Figner et al. 2009; Rosenbaum et al. 2018). Therefore, it seems reasonable to suppose that the impact of high reward sensitivity and poor cognitive control on adolescent risktaking manifests in rewarding rather than non-rewarding conditions. In our study we aimed to test this possibility. We designed a study that includes reward manipulation. To assess risk-taking in adolescents and young adults, we used a driving task that we asked participants to do twice: (1) with rewards based on how quickly participants completed the course; (2) with no rewards. In this two conditions we tested the impact of reward sensitivity and cognitive control on risk-taking. We also used questionnaires to test the impact of self-reported reward sensitivity and self-reported self-control on everyday risk-taking. We decided to test our hypotheses separately at the behavioral and self-report level due to discrepancies in data from tasks and self-reports in risk research (Frey et al. 2017).

We formulated four research hypotheses. We expected that adolescents are more sensitive to rewards than young adults and that this difference in sensitivity would manifest (1) in a greater increase of performance in the incentivized visual search task (measuring reward sensitivity) and (2) in more risk-taking in the driving task when rewarded than nonrewarded. We also expected that (3) risk-taking in the rewarded condition of the driving task is predicted by age, reward sensitivity, cognitive control and impulsivity. Finally, we expected that (4) everyday risk-taking would be predicted by age, self-reported reward sensitivity and selfreported self-control, thus mimicking the effects observed for behavioral tasks.

\section{Method}

\section{Participants}

One hundred and eighty five participants ( 79 men) took part in the study. The sample contained two groups: adolescents $(N=$ 90 , mean age $=14.4, S D=0.68$, range $=[13,16], 40$ boys $)$ and young adults $(N=95$, mean age $=23.05, S D=1.51$, range $=[20,28], 39$ men, university students and people with vocational education). Adolescents were recruited via parentteacher conferences in local schools, while adults were recruited via online advertisements. Parental consent was obtained for all underage participants. Participation was rewarded with vouchers (for a clothing store, a sporting goods store, a bookstore, or a movie theatre) valued from $\$ 5$ to $\$ 15$ (mean $\$ 10$, equivalents in local currency), depending on the level of individual performance in the two rewarded tasks (see below). Participants could win $\$ 5, \$ 7.5, \$ 10, \$ 12.5$ or $\$ 15$, depending on the points they scored. The point ranges for each amount were based on the results of the pilot study, which was conducted on 60 adolescents and young adults.

\section{Procedure}

The research was conducted in schools (adolescents) or at a university (adults). Before the experiment, all subjects were informed about the general purpose of the study and the 
experimental procedure. They were assured anonymity and confidential storage of the collected data. They were also informed that they could withdraw their participation at any time and could receive performance feedback after completing the study. The experiment lasted about $80 \mathrm{~min}$ with a ten-minute break in the middle of the session. Participants performed a set of tasks measuring risk-taking, reward sensitivity, cognitive control, and impulsivity. The order of tasks was randomized. Each task was preceded by a practice session. The amount of the reward was based on performance in two selected tasks (measuring risk-taking and reward sensitivity). The task measuring risk-taking was performed twice: in the rewarded and the non-rewarded conditions (in random order). Only the result from the former was included in the overall reward. At the end of the experiment, participants completed three questionnaires measuring everyday risk-taking, reward sensitivity, and self-control, in a fixed order.

\section{Measures}

Spaceride ${ }^{1}$ The risk-taking measure resembled a racing game with obstacles. The task was similar to the Stoplight task (Chein et al. 2011). The objective was to fly a spaceship through outer space in order to reach the destination in the shortest possible time (see Fig. 1). At any time during the task, participants could press the accelerate or brake key, or not press any of the keys. When participants chose any of the options, the spaceship moved at a constant speed (accordingly, fast, slow or medium). On the route there were 10 danger zones in which the spaceship could collide with a passing asteroid. In each danger zone there was $50 \%$ probability that the asteroid would appear, and the probability of its appearance was distributed uniformly over the whole of each danger zone. Entry into each danger zone was signaled by auditory and visual stimuli (sound signal, a light on a "radar panel", and the appearance of distant, non-threatening, asteroids in the background). When entering a danger zone, the participants could press the accelerate key (or not press anything), thereby risking a collision, or press the brake key to avoid the asteroid. Collisions led to temporary immobilization of the spaceship and consequently prolonged the time of the ride. Our goal was to not encourage participants to use either of the two possible strategies (safe or risky), so the expected time of flight when the safe strategy (using the brake key through the entire danger zone) was chosen equaled the expected time of flight when the risky strategy (pressing the accelerate button) was chosen. The former was $17 \mathrm{~s}$, while the latter could be $7 \mathrm{~s}$ if no asteroid was hit $(50 \%$ chance) or $26 \mathrm{~s}$ ( $7 \mathrm{~s}$ of flight plus $19 \mathrm{~s}$ of punitive immobilization) if an asteroid was hit (50\% chance).

\footnotetext{
${ }^{1}$ All experimental tasks are available in the OSF repository: https://doi.org/10. 17605/OSF.IO/8EHCB
}

The measure of risk-taking was the proportion of collisions to the number of danger zones in which the asteroid appeared (i.e. the maximum possible number of collisions).

Incentivized Visual Search Task (IVS) We created a new task to measure reward sensitivity, operationalized as an increase in visual search performance along with the growing value of rewards. A $12 \times 10$ matrix of five-, six- and seven-pointed stars was presented on the screen. The goal was to search for and mark six-pointed stars by scanning the field from left to right, row by row (see Fig. A in the Supplement). Participants had $30 \mathrm{~s}$ to find all six-pointed stars. After this time they were asked to mark the location of the last scanned star (signal or noise) so we were able to measure the scanned area and estimate the speed of their processing. The task consisted of 16 blocks, each of which varied in the amount of points the participants could get for correct detection. Depending on the block, the reward was $0,1,2$ or 5 points for each correctly marked target (out of 10 in every block). There were four blocks for each reward value and the order of the blocks was randomized (except for the first turn, which was always scored 1 point to establish a reference point). Additionally, to prevent the strategy of marking all stars (correct and wrong) to maximize the score, at each turn participants lost 1 point for marking a wrong star. The value of the reward in points appeared before each block on the screen; the number of points scored was displayed after each session.

The difference between correctly indicated stimuli and false alarms was a basic performance measure. To assess participants' individual reward sensitivity, we fitted a mixed linear model for which basic performance in the IVS task was assumed to be logarithmically dependent on the reward value. In the model this dependence included the random effect of participants, so we obtained an individual estimation of the performance increase parameter over the $(\log )$ reward value for every participant $(F[11,058.5]=30.39, p<.001$, marginal $R^{2}=.011$, conditional $R^{2}=.3$ ). These individual estimations were used as a measure of reward sensitivity.

Go/no-Go Task This task is a popular measure of response inhibition (e.g. Logan 1994). In "go" trials, participants categorized numbers appearing on the screen as even or odd, but in "no-go" trials (i.e. when a specific number, indicated in the instructions, appeared on screen) they had to refrain from reacting. The version of the task used in this study consisted of 10 blocks, each containing 10 trials (on average 8.33 "go" and 1.67 "no go" trials). The display time of stimuli was $1 \mathrm{~s}$; the criterion according to which it was necessary to react changed every block.

The measure of participants' cognitive control was $d^{\prime}$; this is a complex measure based on signal detection theory that takes into account both hits and false alarms. 

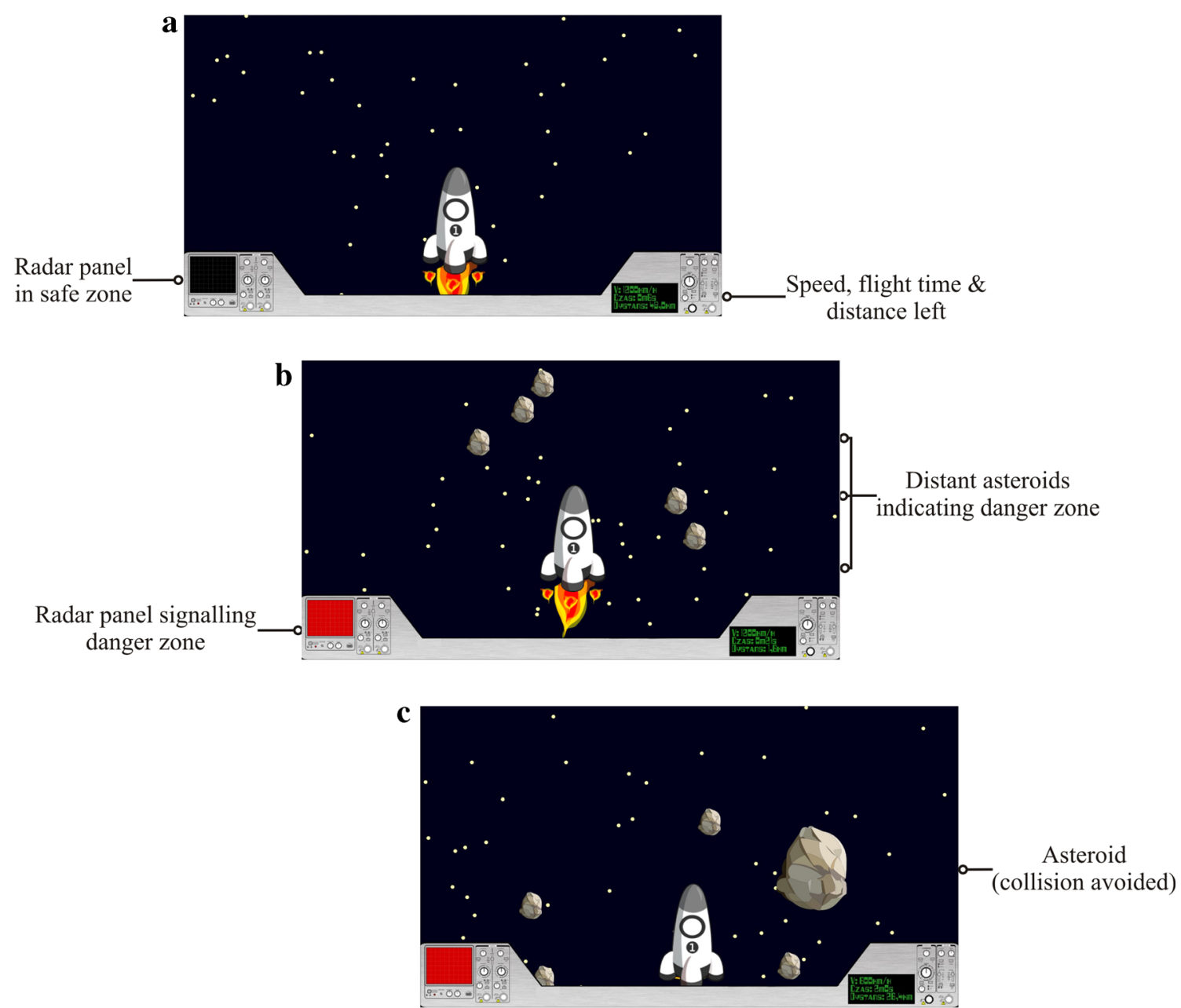

Fig. 1 Screens of the Spaceride task: (A) Safe zone view, (B) Danger zone without asteroid view, (C) Danger zone with asteroid view (collision avoided)

Matching Familiar Figures Test (MFF) We measured impulsivity using Kagan's MFF Test (Matczak and Kagan 1992). The test consisted of 12 trials, in each of which participants were shown a black-and-white reference picture (e.g. a house, scissors, a telephone or a tree) and six visually similar test pictures that differed in small details. The goal in each trial was to find the drawing that was identical to the reference picture. Both the reference picture and all optional pictures were visible all the time, so the task did not involve visual memory. Both response time and accuracy were recorded. There are two simple strategies which can be used to solve the task. The first (impulsive - fast and incorrect) is to answer as soon as one sees a picture which matches the reference picture. The second (deliberate - slow and accurate) is to delay answering until one achieves a high certainty that there are no differences between the model and the match.

Since there are two simple measures of this impulsivity (speed and accuracy), both of which are equally theoretically valid, a complex measure of this variable was used in the task. As they were correlated $(r=-.45,95 \% C I=[-.56,-.33])$, we used the main principal component of these variables as a unified measure of impulsivity.
Risk Behavior Questionnaire This is a new measure based on the Adolescent Risk-Taking Questionnaire (ARQ; Gullone et al. 2000), in which participants assess the frequency of risky behaviors using a 5-point scale from 1 - "have never done it" to 5 - "[I do it] very often". As the ARQ was developed to study adolescents aged 11-18 years, we modified it in the pilot study (in 197 adolescents and young adults) to make it applicable for all our age samples by adding items describing risk behaviors that are typical of young adults. After the pilot study's data analysis, we removed items with the lowest reliability. The final version included 29 risky behaviors (we present it in Table A in the Supplement). The Cronbach's $\alpha$ of the questionnaire was $.86,95 \% C I=[.83, .89]$. The mean response to all items was the measure of everyday risk-taking.

Short Form of the Sensitivity to Punishment and Sensitivity to Reward Questionnaire (SPSRQ-SF) We used the Cooper and Gomez questionnaire adapted by Wytykowska et al. (2014). This questionnaire consists of 24 yes-no statements and measures individual sensitivity of the Behavioral Inhibition System (BIS) and the Behavioral Approach System (BAS) 
with separate subscales. The Cronbach's $\alpha$ of the Sensitivity to Punishment subscale was $.81,95 \% C I=[.77, .85]$, and for the Sensitivity to Reward subscale it was $.71,95 \% C I=[.65$, .77]. The mean response to all items in the Sensitivity to Reward subscale was the measure of reward sensitivity. The Sensitivity to Punishment subscale was not analyzed in this study.

Self-Knowledge New Sheet (NAS-50) A questionnaire created by Nęcka et al. (2016) for assessment of self-control. The scale consists of 50 items divided into 5 subscales: goal maintenance, proactive control, initiative and persistence, switching and flexibility, inhibition and adjournment. The answers are assessed on a 5-point scale from 1 - "definitely not" to 5 - "definitely yes". Cronbach's $\alpha$ in the present investigation was $.87,95 \% C I=[.84, .89]$. The mean response to all items was the measure of self-control.

\section{Statistical Analyses}

The analyses of the data were conducted using $\mathrm{R}$ ( $\mathrm{R}$ Core Team 2019). The effects of reward sensitivity and cognitive control on risk-taking have been tested on two levels: in behavioral tasks and in self-report measures. In the first case, we fitted a linear model for which risk-taking in the both rewarded and non-rewarded conditions of the Spaceride task depended on reward sensitivity (measured by the IVS task), cognitive control (in the Go/No-go task), impulsivity (in the MFF test), age group, and interactions between the age group and reward sensitivity and cognitive control. Additionally, we controlled for gender, group relative age (difference between age and the mean age for the age group) since some variance in age remained after dichotomization to adolescents and adults, and braking (duration of pressing the brake key in danger zones with the asteroid in the Spaceride task) since it could have a large impact on the dependent variable, i.e. frequency of crashing. On the self-report level we fitted a similar linear model to assess the relationship between everyday risktaking, measured with the Risk Behavior Questionnaire (dependent variable), and reward sensitivity (measured with SPSRQ-SF), self-control (measured with NAS-50), age group, and interactions between SPSRQ-SF, NAS-50 and age group. For all significant effects we provide partial $R^{2}$ as a measure of effect size.

\section{Results}

Table 1 presents descriptive statistics and correlations for all measures; Table 2 presents a comparison of mean value for all measures, taking into account the age group (adolescents vs. young adults).
Reward Sensitivity in the Incentivized Visual Search Task (IVS) Firstly, we assessed performance and tested the first hypothesis concerning difference between adolescents and adults in reward sensitivity in the IVS Task. Two participants (one from each age group) did not finish the task. We found no difference between adolescents and adults in performance $\left(F[1186.42]=0.33, p=.57, R^{2}=.016\right)$. We found that adolescents were more sensitive to rewards than adults $(\beta=0.16$, $F[1178]=4.63, p=.033$, partial $R^{2}=.02$ ), which means the logarithmic increase of performance along with the increase of rewards $(0,1,2$ or 5 points for each correct indication) was greater in adolescents than in adults (see Fig. 2).

The Effect of Rewards on Risk-Taking in the Spaceride Task Secondly, we investigated the effect of rewards on risk-taking and tested the second hypothesis concerning differences between adolescents and adults in rewarded vs. non-rewarded condition of the Spaceride task. The linear mixed model was fitted to the data (with random effect of participants on the intercept, see Table 3 for the Anova table). We found no difference in risk-taking between adults and adolescents $(F[1175.98]=0.14, p=.71)$, nor between the rewarded and non-rewarded condition $(F[11,743.69]=0.5, p=.48)$. However, there appeared to be an interaction between these variables: adolescents, but not adults, risked more in the rewarded than in the non-rewarded condition $(F[1$, $1744.92]=5.98, p=.015$, partial $R^{2}=.002$, see Fig. 3).

Predictors of Risk-Taking in the Spaceride Task Thirdly, we tested the hypothesis considering age, reward sensitivity, cognitive control and impulsivity as predictors of risk-taking in the rewarded vs. non-rewarded condition of the Spaceride task. No significant predictors were identified in the nonrewarded condition. In particular the interaction between age group and reward sensitivity was not significant $(F[1,162]=$ $0.16, p=.69$, see Fig. 4, left panel). The Anova table of the model is presented in Table B in the Supplement.

On the other hand, there appeared to be an interactive effect of age group and reward sensitivity in the rewarded condition $\left(F[1,162]=4.48, p=.036\right.$, partial $\left.R^{2}=.029\right)$. The higher the reward sensitivity, the more adolescents risked compared to adults (see Fig. 4, right panel). The Anova table of the model is presented in Table 4 . There were no simple main effects of either cognitive control or impulsivity on risk-taking in either of the models.

Predictors of Everyday Risk-Taking Finally, we tested the fourth hypothesis considering age, self-reported reward sensitivity and self-control as predictors of everyday risk-taking. Both age group and gender had a relationship with risk-taking (adults risked more than adolescents, $F[1,177]=4.99$, $p=.027$, partial $R^{2}=.032$; men risked more than women, $F[1,177]=16, p<.001$, partial $\left.R^{2}=.064\right)$. Self-reported 


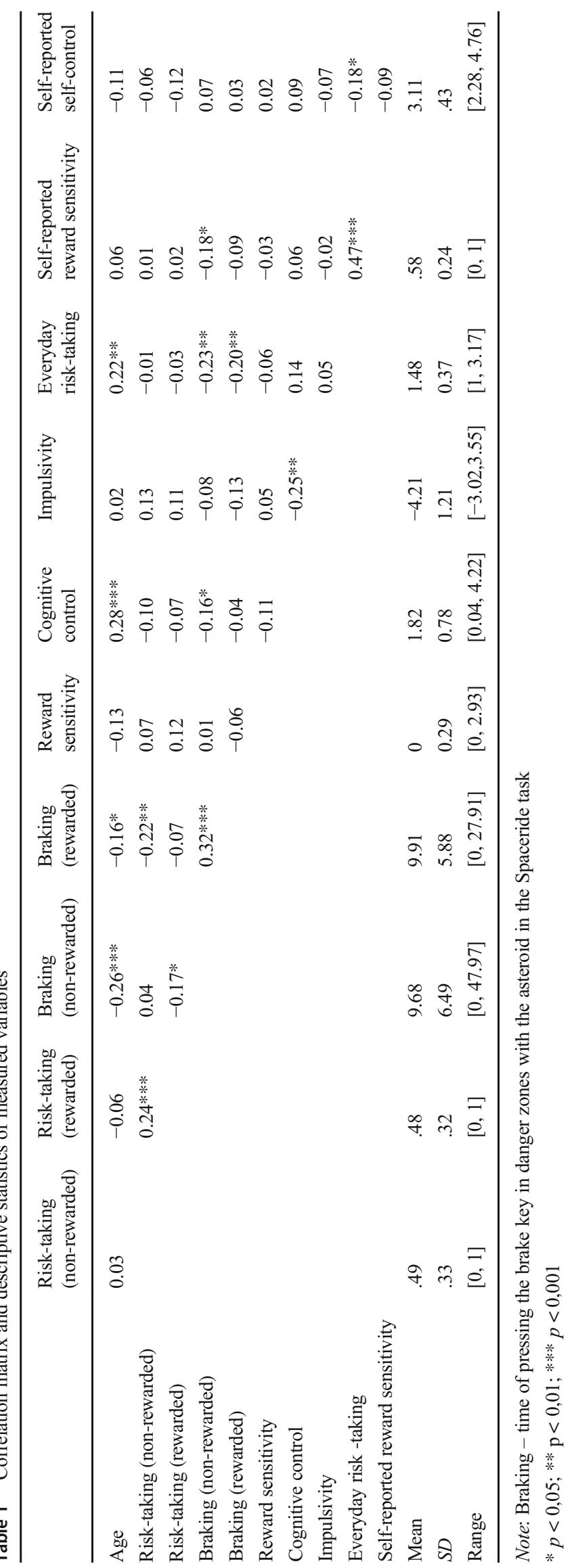


Table 2 The means of measured variables considering age group and results of the comparison tests

\begin{tabular}{lccccc}
\hline & $\begin{array}{l}\text { Mean for } \\
\text { adolescents }\end{array}$ & Mean for adults & $t(d f)$ & $W$ & $p$ \\
\hline Risk-taking (non-rewarded) & .48 & .49 & & 4218 & .88 \\
Risk-taking (rewarded) & .5 & .6 & 4598 & .37 \\
Braking (non-rewarded) & 11.63 & 7.83 & 5921 & $<.001 * * *$ \\
Braking (rewarded) & 10.91 & 8.96 & 4920 & .077 \\
Reward sensitivity & 0.05 & -0.04 & $-0.25(182.74)$ & & $.042 *$ \\
Cognitive control & 1.57 & 2.04 & & 3091 & .001 \\
Impulsivity & -0.02 & 0.02 & & 3816.5 & .21 \\
Everyday risk-taking & 1.41 & 1.55 & 4857.5 & .11 \\
Self-reported reward sensitivity & 0.56 & 0.6 & & & $.001 * * *$ \\
Self-reported self-control & 3.39 & 3.28 & & & \\
\hline
\end{tabular}

Note: For the impulsivity the difference was tested with the Welch two sample $t$-test. For other variables the Wilcoxon rank sum test with continuity correction was used due to non-normality of at least one of the tested groups

$* \mathrm{p}<0,05 ; * * \mathrm{p}<0,01 ; * * * \mathrm{p}<0,001$ reward sensitivity appeared to have a positive relationship with everyday risk-taking $(F[1,177]=59.72, p<.001$, partial $\left.R^{2}=.15\right)$. We also found a simple negative effect of selfcontrol on risk-taking but the effect was marginal $(F[1$, $177]=5.01, p=.026$, partial $\left.R^{2}=.001\right)$. Neither self-reported reward sensitivity nor self-control were significant predictors of everyday risk-taking in the interaction with the age group (see Table 5 for Anova table).

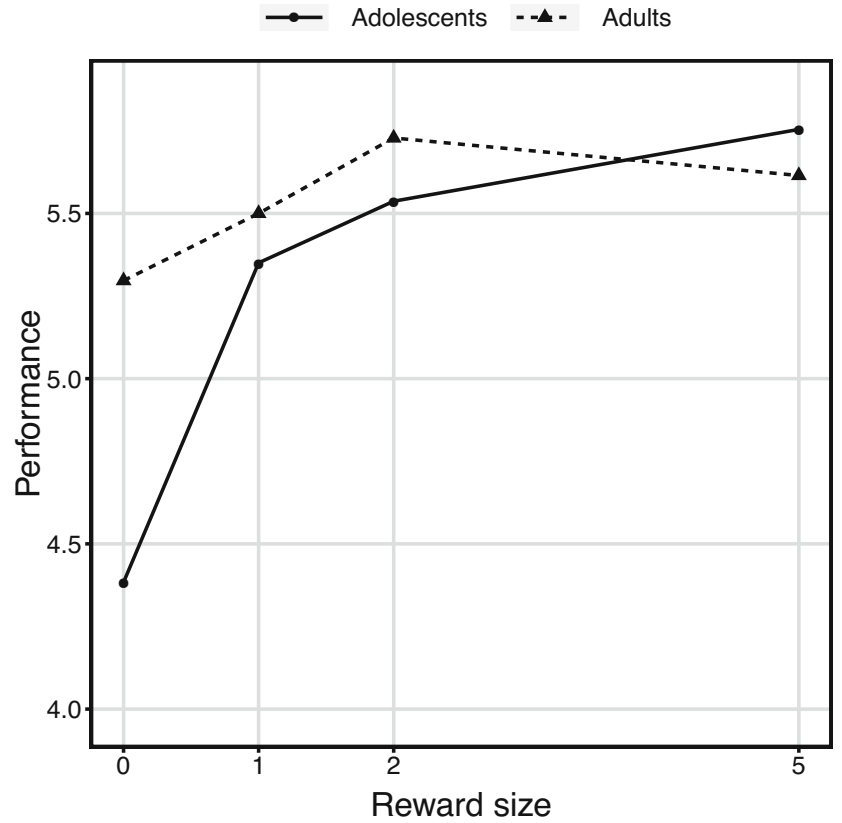

Fig. 2 Logarithmic relationship between reward size and performance in the Incentivized Visual Search Task for adolescents (solid line) and adults (dashed line)

\section{Discussion}

According to the first tested hypothesis, considering differences between adolescents and adults in reward sensitivity, we found that adolescents are more sensitive to rewards than adults in the Incentivized Visual Search Task, and this difference in sensitivity manifests in a slightly greater increase of performance as the value of rewards increases $(0,1,2$ or 5 points for each correctly marked target). Although the literature does not give a clear answer on whether adolescents respond differently than adults to increasing rewards (Kray et al. 2018), the effect observed for the IVS Task can be compared with the results of Bjork et al. (2010). The authors observed that both adolescents and adults respond faster and are more accurate as the size of rewards increases $(0,50$ cents or 5 dollar blocks) in a monetary task.

According to the second tested hypothesis, considering differences between adolescents and adults in risk-taking in rewarded vs. non-rewarded driving task, we found that adolescents, but not adults, risk more in the rewarded than in the non-rewarded condition. The observed effect of interaction, although small, is evidence that adolescent risk-taking increases in the presence of rewards; however, this does not mean that adolescents risk more than adults in the rewarded condition. Rather, they risk slightly less than adults in the nonrewarded condition and reach the level of adults when rewarded. Our finding is quite similar to the results of Figner et al. (2009), who tested arousing and non-arousing versions of the Columbia Card Task in adolescents and adults (feedback, not reward manipulation, was used). The authors showed that adolescents risk more than adults in the arousing version of the task, and that risk-taking in the arousing relative to non-arousing version is higher in both age groups. There 
Table 3 Type III Analysis of Variance Table with Satterthwaite's method. The dependent variable was risktaking in the Spaceride task

\begin{tabular}{llccrc}
\hline & $d f$ (numerator) & $d f$ (denominator) & Sum of squares & $F$ & $p$ \\
\hline Age group & 1 & 175.98 & 0.02 & 0.14 & .71 \\
Condition & 1 & 1743.69 & 0.07 & 0.5 & .48 \\
Gender & 1 & 172.97 & 0.44 & 3.29 & .07 \\
Group relative age & 1 & 172.14 & 0.06 & 0.45 & .5 \\
Braking & 1 & 1832.29 & 63.69 & 480.17 & $<.001^{* * *}$ \\
Accelerating & 1 & 1871 & 100.39 & 756.85 & $<.001^{* * *}$ \\
Turn number & 1 & 1756.25 & 4.7 & 35.4 & $<.001^{* * *}$ \\
Age group $\times$ Condition & 1 & 1744.92 & 0.79 & 5.98 & $.015^{*}$ \\
\hline
\end{tabular}

$* \mathrm{p}<0,05 ; * * \mathrm{p}<0,01 ; * * * \mathrm{p}<0,001$ may be various explanations for why adolescents in our task risked more in the presence of rewards but do not exceed the level of adults. For example, it is possible that they are not only more sensitive to rewards but also to collisions (and this can reduce their risk propensity). It should also be noted that risk-taking measured with different behavioral tasks does not always peak in mid-adolescence, as demonstrated by Duell et al. (2016).

Our third hypothesis considered age, reward sensitivity, cognitive control and impulsivity as predictors of risk-taking in the rewarded vs. non-rewarded condition of the driving task. In line with this hypothesis, we found that the higher the reward sensitivity, the more adolescents risk, compared to adults, in the rewarded condition. The observed effect is consistent with the Dual Systems Model (Shulman et al. 2016;

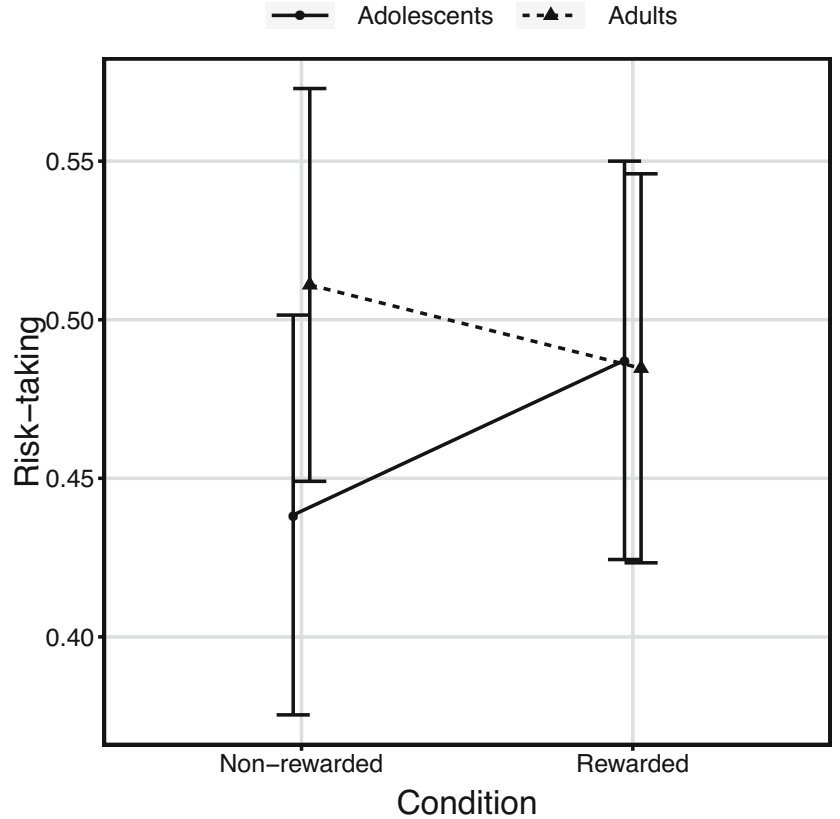

Fig. 3 Risk-taking in the Spaceride task depending on condition (nonrewarded vs. rewarded) and age group (adolescents vs. adults). Bars indicate $95 \%$ confidence intervals
Rosenbaum et al. 2018) and supports the supposition that the impact of risk predictors is more visible in rewarding conditions. Although it can be seen that the effect is small, this is not surprising when we consider that reward sensitivity and risk-taking usually correlate weakly when measured with separate behavioral tasks (e.g. Duell et al. 2016).

Contrary to the third hypothesis, we found no impact of cognitive control or impulsivity on risk-taking, regardless of age and condition. This means that the impact of the tested variables may be not visible even if the risk is taken in the presence of rewards. When comparing our findings with the research of other authors (e.g. Duell et al. 2016), it can be seen that correlations between risk-taking and cognitive control measured with behavioral tasks are usually weak or nonexistent. Some of the possible explanations for this are of a more general nature: for example, the impact of cognitive control may be more apparent in Western and high-GDP countries (Duell et al. 2016) or in subgroups of people with problem behavior (Bjork and Pardini 2015; Romer et al. 2017). There are also explanations of a more detailed nature: the impact of cognitive control may be not visible unless it is tested under arousal (Botdorf et al. 2017), or cognitive control may affect task performance rather than risk-taking (Blair et al. 2018; see also Figner et al. 2009). The last-mentioned possibility means that poor cognitive control may not necessarily enhance risktaking; instead, it may reduce the ability to learn which strategy in a task is optimal (Figner et al. 2009). Thus, when both possible strategies (safe and risky) in a risk task are equally good, cognitive control may be not relevant for either risk-taking or task performance (as in our study).

Our last, fourth hypothesis considered age, self-reported reward sensitivity, and self-control as predictors of everyday risk-taking. In line with the hypothesis, we found that the higher the reward sensitivity and the poorer the self-control, the more risk-taking participants report. Our finding is 
Fig. 4 Risk-taking in the Spaceride task in relation to reward sensitivity measured in the Incentivized Visual Search Task, depending on condition (nonrewarded, left panel vs. rewarded, right panel) and age group (adolescents, solid line vs. adults dashed line). Bars indicate 95\% confidence intervals

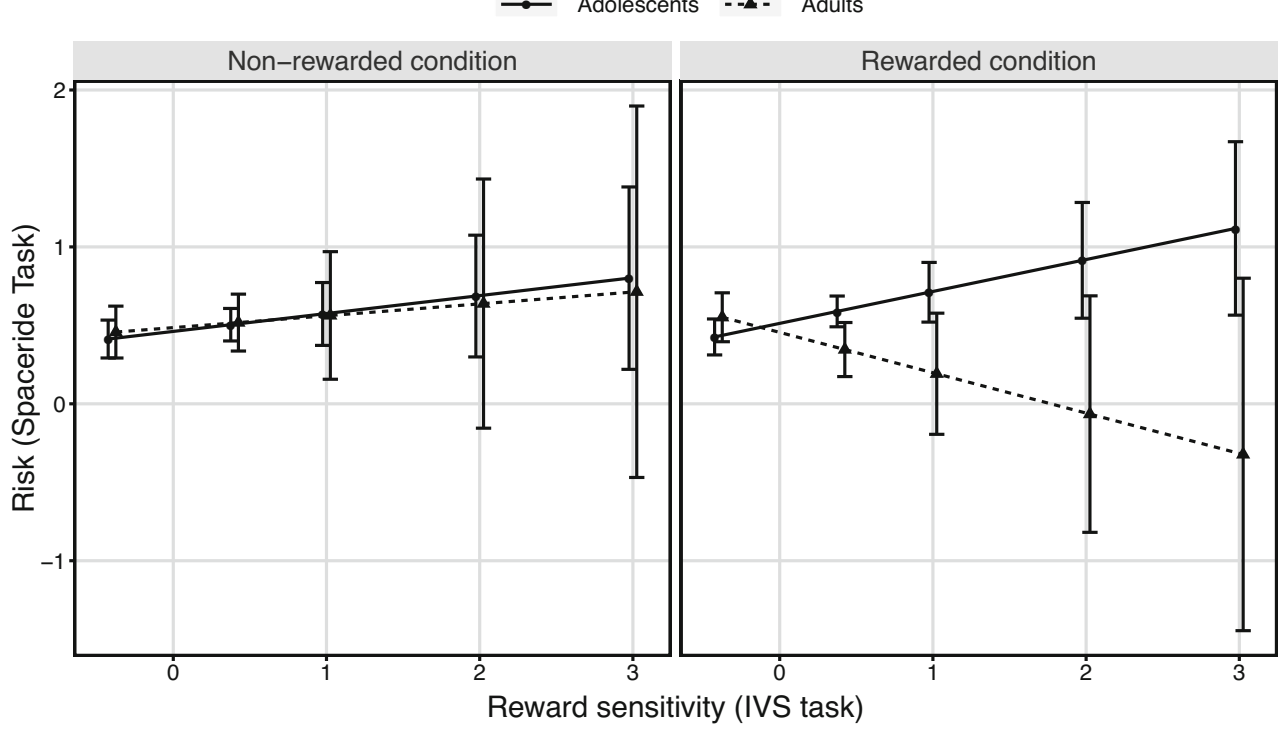

consistent with the results of authors who have shown that both variables affect risk-taking, but its impact is not unique to adolescence (e.g. Duell et al. 2016). When we compare our results from self-reports and behavioral tasks, it can be seen that the effect of reward sensitivity observed for self-reports mimics the effect observed for behavioral tasks, but it is larger (in the sense of explained variance) and not limited to adolescence. The effect of self-control on everyday risk-taking is marginal and does not reflect anything at the behavioral level. It is possible that everyday risk-taking, especially negative risks such as rule breaking and substance use, are more visibly related to control processes (Kim-Spoon et al. 2016; Peeters et al. 2017; Vazsonyi and Ksinan 2017).

Table 4 Analysis of Variance Table. The dependent variable was risktaking in the rewarded condition of the Spaceride task

\begin{tabular}{lllll}
\hline & $d f$ & Sum of squares & $F$ & $p$ \\
\hline Age group & 1 & 0.1 & 0.95 & .33 \\
Reward sensitivity (IVS task) & 1 & 0.2 & 2.02 & .15 \\
Cognitive control (Go/no go task) & 1 & 0.03 & 0.26 & .61 \\
Impulsivity (MFF Test) & 1 & 0.06 & 0.62 & .43 \\
Gender & 1 & 0.36 & 3.6 & .06 \\
Group relative age & 1 & 0 & 0.03 & .87 \\
Braking (Spaceride task) & 1 & 0.06 & 0.58 & .45 \\
Age group $\times$ Reward sensitivity & 1 & 0.45 & 4.48 & $0.036^{*}$ \\
Age group $\times$ Cognitive control & 1 & 0.05 & 0.53 & .47 \\
Residuals & 162 & & & \\
\hline
\end{tabular}

Note: Adjusted $R^{2}=.023, F[9,162]=1.45, p<.001$

$* p<.05, * * p<.01, * * *, p<.001$
In conclusion, the purpose of our study was to test whether adolescent risk-taking results from high reward sensitivity and poor cognitive control. Although this issue has recently been the subject of research by other authors (e.g. Duell et al. 2016; Meisel et al. 2019), our study is the first that attempts to examine whether the impact of both variables is more visible when risk is taken in rewarded than in non-rewarded conditions. In addition, examining the impact of reward sensitivity and cognitive control on risk-taking separately at the behavioral and the self-report levels allows us to see whether the effects observed for self-reports mimic the effects observed for behavioral tasks.

Table 5 Analysis of Variance Table. The dependent variable was everyday risk-taking (Risk Behavior Questionnaire)

\begin{tabular}{|c|c|c|c|c|}
\hline & $d f$ & $\begin{array}{l}\text { Sum of } \\
\text { squares }\end{array}$ & $F$ & $p$ \\
\hline Age group & 1 & 0.46 & 4.99 & $.027 *$ \\
\hline $\begin{array}{l}\text { Self-reported reward } \\
\text { sensitivity (SPSRQ-SF) }\end{array}$ & 1 & 5.48 & 59.72 & $<.001 * * *$ \\
\hline $\begin{array}{l}\text { Self-reported } \\
\quad \text { self-control (NAS-50) }\end{array}$ & 1 & 0.46 & 5.01 & $.026^{*}$ \\
\hline Gender & 1 & 1.47 & 16 & $<.001 * * *$ \\
\hline Group relative age & 1 & 0.5 & 5.48 & $.02 *$ \\
\hline $\begin{array}{l}\text { Age group } \times \text { Self-reported } \\
\text { reward sensitivity }\end{array}$ & 1 & 0.26 & 2.87 & .092 \\
\hline $\begin{array}{l}\text { Age group } \times \text { Self-reported } \\
\text { self-control }\end{array}$ & 1 & 0.22 & 2.42 & .12 \\
\hline Residuals & 177 & & & \\
\hline
\end{tabular}

Note: Adjusted $R^{2}=.33 . F[7,177]=13.78 . p<.001$

$* p<.05 . * * p<.01 . * * * . p<.001$ 
Supplementary Information The online version contains supplementary material available at https://doi.org/10.1007/s12144-021-01769-6.

Availability of Data and Material The datasets generated and analyzed during the current study are available in the OSF repository, https://doi. org/10.17605/OSF.IO/8EHCB.

Code Availability Not applicable.

Authors' Contribution All authors contributed to the study conception and design. Material preparation and data collection were performed by Joanna Fryt, Karolina Czernecka, Monika Szczygieł and Amelia LaTorre. Data analysis was performed by Tomasz Smolen. The first draft of the manuscript was written by Joanna Fryt and Tomasz Smolen, and all authors commented on previous versions of the manuscript. All authors read and approved the final manuscript

Funding This work was funded by the National Science Centre, Poland (grant 2015/18/E/HS6/00152).

\section{Declarations}

Ethical Approval All procedures performed in the study are in accordance with the ethical standards of the institutional research committee and with the Helsinki declaration.

Consent to Participate Informed consent was obtained from all individual participants included in the study.

Consent to Publish Not applicable.

Conflict of Interest The authors declare that they have no conflicts of interest that could influence or bias the work.

Open Access This article is licensed under a Creative Commons Attribution 4.0 International License, which permits use, sharing, adaptation, distribution and reproduction in any medium or format, as long as you give appropriate credit to the original author(s) and the source, provide a link to the Creative Commons licence, and indicate if changes were made. The images or other third party material in this article are included in the article's Creative Commons licence, unless indicated otherwise in a credit line to the material. If material is not included in the article's Creative Commons licence and your intended use is not permitted by statutory regulation or exceeds the permitted use, you will need to obtain permission directly from the copyright holder. To view a copy of this licence, visit http://creativecommons.org/licenses/by/4.0/.

\section{References}

Bjork, J. M., \& Pardini, D. A. (2015). Who are those "risk-taking adolescents"? Individual differences in neurodevelopmental research. Developmental Cognitive Neuroscience, 11, 56-64.

Bjork, J. M., Smith, A. R., Chen, G., \& Hommer, D. W. (2010). Adolescents, adults and rewards: Comparing motivational neurocircuitry recruitment using fMRI. PLoS One, 7(5), e11440.

Blair, M. A., Moyett, A., Bato, A. A., DeRosse, P., \& Karlsgodt, K. H. (2018). The role of executive function in adolescent adaptive risk taking on the balloon analogue risk task. Developmental Neuropsychology, 43(7), 566-580.

Botdorf, M., Rosenbaum, G. M., Patrianakos, J., Steinberg, L., \& Chein, J. (2017). Adolescent risk-taking is predicted by individual differences in cognitive control over emotional, but not non-emotional, response conflict. Cognition \& Emotion, 31(5), 972-979.

Casey, B. J., Getz, S., \& Galvan, A. (2008). The adolescent brain. Developmental Review, 28(1), 62-77.

Casey, B. J. (2015). Beyond simple models of self-control to circuitbased accounts of adolescent behavior. Annual Review of Psychology, 3(66), 295-319.

Chein, J., Albert, D., O’Brien, L., Uckert, K., \& Steinberg, L. (2011). Peers increase adolescent risk taking by enhancing activity in brain's reward circuitry. Developmental Science, 14(2), F1-F10.

Crone, E. A., \& Steinbeis, N. (2017). Neural perspectives on cognitive control development during childhood and adolescence. Trends in Cognitive Science, 21(3), 205-215.

Defoe, I. N., Dubas, J. S., Figner, B., \& van Aken, M. A. (2015). A metaanalysis on age-differences in risky decision making: Adolescents versus children and adults. Psychological Bulletin, 141(1), 48-84.

Duell, N., Steinberg, L., Chein, J., Al-Hassan, S., Bacchini, D., Lei, C., et al. (2016). Interaction of reward seeking and self-regulation in the prediction of risk taking: A cross-national test of the dual systems model. Developmental Psychology, 52(10), 1593-1605.

Duijvenvoorde, A. C. K., Huizenga, H. M., Somerville, L. H., Delgado, M. R., Powers, A., Weeda, W. D., et al. (2015). Neural correlates of expected risk and returns in risky choice across development. The Journal of Neuroscience, 35(4), 1549-1560.

Duijvenvoorde, A. C. K., Peters, S., Braams, B. R., \& Crone, E. (2016). What motivates adolescents? Neural responses to rewards and their influence on adolescents' risk taking, learning, and cognitive control. Neuroscience \& Biobehavioral Reviews, 70, 135-147.

Figner, B., Mackinlay, R. J., Wilkening, F., \& Weber, E. U. (2009). Affective and deliberative processes in risky choice: Age differences in risk taking in the Columbia card task. Journal of Experimental Psychology: Learning, Memory and Cognition, 35, 709-730.

Figner, B., \& Weber, E. U. (2011). Who takes risk, when and why? Determinants of risk taking. Current Directions on Psychological Science, 20(4), 211-216.

Frey, R., Perdoni, A., Mata, R., Rieskamp, J., \& Hertwig, R. (2017). Risk preferences shares the psychometric structure of major psychological traits. Science Advances, 3(10), e1701381.

Gullone, E., Moore, S., Moss, S., \& Boyd, C. (2000). The adolescent risktaking questionnaire: Development and psychometric evaluation. Journal of Adolescent Research, 15, 231-250.

Harden, K. P., Quinn, P. D., \& Tucker-Drob, E. M. (2012). Genetically influence change in sensation seeking drives the rise in delinquent behavior during adolescence. Developmental Science, 15(1), 150 163.

Harden, K. P., Kretsch, N., Mann, F. D., Herzhoff, K., Tackett, J. L., Steinberg, L., \& Tucker-Drob, E. M. (2017). Beyond dual systems: A genetically-informed, latent factor model of behavioral and selfreport measures related to adolescent risk-taking. Developmental Cognitive Neuroscience, 25, 221-234.

Kim-Spoon, J., Deater-Deckard, K., Holmes, C., Lee, J., Chiu, P., \& King-Casas, B. (2016). Behavioral and neural inhibitory control moderates the effects of reward sensitivity on adolescent substance use. Neuropsychologia, 91, 318-326.

Kray, J., Schmitt, H., Lorenz, C., \& Ferdinand, N. K. (2018). The influence of different kinds of incentives on decision making and cognitive control in adolescent development: A review of behavioral and neuroscientific studies. Frontiers in Psychology, 9, 768.

Logan, G. D. (1994). On the ability to inhibit thought and action: A users guide to the stop signal paradigm. In D. Dagenbach \& T. H. Carr (Eds.), Inhibitory processes in attention, memory, and language (pp. 189-239). Academic Press. 
Luna, B., \& Wright, C. (2016). Adolescent brain development: Implications to the juvenile criminal justice system. In K. Heilbrun (Ed.), APA handbooks in psychology: APA handbook of psychology and juvenile justice. American Psychological Association.

Matczak, A., \& Kagan, J. (1992). Test Porównywania Znanych Ksztaltów (MFF) J. Kagana: podręcznik. [Matching Familiar Figures Test (MFF) of J. Kagan: A handbook.] Warszawa: Pracownia Testów Psychologicznych Polskiego Towarzystwa Psychologicznego.

Meisel, S. N., Fosco, W. D., Hawk, L. W., \& Colder, C. R. (2019). Mind the gap: A review and recommendation for statistically evaluating dual systems models of adolescent risk-taking behavior. Developmental Cognitive Neuroscience, 39, 100681.

Nęcka, E., Wujcik, R., Orzechowski, J., Gruszka, A., Janik, B., Nowak, M., \& Wójcik, N. (2016). NAS-50 and NAS-40: New scales for assessment of self-control. Polish Psychological Bulletin, 47(3), 346-355.

Peeters, M., Oldehinkel, T., \& Vollebergh, W. (2017). Behavioral control and reward sensitivity in adolescents' risk taking behavior: A longitudinal TRAILS study. Frontiers in Psychology, 8, 231.

Qu, Y., Galvan, A., Fuligni, A. J., Lieberman, M. D., \& Telzer, E. H. (2015). Longitudinal changes in prefrontal cortex activation underlie declines in adolescent risk taking. The Journal of Neuroscience, 35(32), 11308-11314.

R Core Team (2019). R: A language and environment for statistical computing [computer software manual]. Vienna, Austria. Retrieved from https://www.R-project.org/
Romer, D., Reyna, V. F., \& Satterthwaite, T. (2017). Beyond stereotypes of adolescent risk taking: Placing the adolescent brain in developmental context. Developmental Cognitive Neuroscience, 27, 19-34.

Rosenbaum, G. M., Venkatraman, V., Steinberg, L., \& Chein, J. M. (2018). The influences of described and experienced information on adolescent risky decision making. Developmental Review, 47, $23-43$.

Shulman, E. P., Smith, A. R., Silva, K., Icenogle, G., Duell, B., Chein, J., \& Steinberg, L. (2016). The dual systems model: Review, reappraisal, and reaffirmation. Developmental Cognitive Neuroscience, 17, $103-117$.

Steinberg, L. (2008). A social neuroscience perspective on adolescent risk taking. Developmental Review, 28, 78-106.

Vazsonyi, A. T., \& Ksinan, A. J. (2017). Understanding deviance through the dual systems model: Converging evidence for criminology and developmental sciences. Personality and Individual Differences, $111,58-64$.

Wytykowska, A., Białaszek, W., \& Ostaszewski, P. (2014). Psychometryczne właściwości polskiej wersji Krótkiej Skali Wrażliwości na Kary i Nagrody (SPSRQ-SF Cooper i Gomez, 2008). [Psychometric parameters of the Polish short version of sensitivity to punishment and reward scale.] Studia Psychologiczne, 52, $2,28-39$.

Publisher's Note Springer Nature remains neutral with regard to jurisdictional claims in published maps and institutional affiliations. 